\title{
Quantitative and qualitative enumeration of soil mycoflora in brinjal crop fields
}

\author{
Ramaraju Cherkupally ${ }^{1 *}$, Hindumathi Amballa ${ }^{1}$, Bhumi Narasimha Reddy ${ }^{2}$ \\ ${ }^{1}$ Department of Botany, K.R.R. Government Arts and Science College, Kodad, Telangana, India, ²Department of Botany, Osmania \\ University, Hyderabad, Telangana, India
}

Received: 26.07 .2017

Accepted: 18.09.2017

Published: 26.09.2017

*Address for correspondence:

Ramaraju Cherkupally,

Department of Botany,

K.R.R. Government Arts

and Science College,

Kodad, Telangana, India.

E-mail: ramaraj.e789@

gmail.com

\begin{abstract}
A total of 36 species of fungi belonging to 15 genera were isolated from brinjal crop fields of Kodad. The present study results clearly revealed that the rhizosphere and non-rhizosphere soil showed variation in diversity of mycoflora. Aspergillus was observed to be an important component of the present rhizosphere and nonrhizosphere soil fungal flora constituting $70.54 \%$ and $58.96 \%$, respectively, and Aspergillus niger was observed to be predominant species in the rhizosphere and non-rhizosphere soils.
\end{abstract}

KEY WORDS: Microflora, non-rhizosphere, rhizosphere

\section{INTRODUCTION}

Soil is a complex ecosystem. Many biological processes take place in the soil. Soil is a medium with solids, liquids, and gases in which minerals and organic particles form differently sized aggregates that delimit pores. Soil organic matter plays an important role in determining the fertility and productivity of soils (Tisdall and Oades, 1982; Feller and Beare, 1997). This organization creates microenvironments that are suited for microbial activities to the various extents (Chotte et al., 1997). Microorganisms are beneficial in increasing the soil fertility and plant growth as they are involved in several biochemical transformation and mineralization activities in soil. Natural and anthropogenic disturbances can alter the species composition or may have a negative effect on species diversity of decomposer fungi. These changes may directly or indirectly affect the vital functions of the soil such as decomposition and mineralization and may result in disturbances.

Fungi are fundamental for soil ecosystem functioning (Warcup, 1951). Along with bacteria, actinomycetes, and algae, fungi are primary decomposers, agents of biogeochemical transformations and recyclers of stored energy and nutrients of the organic matter already degraded by invertebrates and other microbes for plant growth. The organic and inorganic materials present in the soil have a direct effect on the fungal population of the soil.
The members and kinds of microorganisms present in the soil depend on many environmental factors such as amount and type of nutrients, moisture, degree of aeration, $\mathrm{pH}$, and temperature (Gaddeyya et al., 2012). Rhizosphere is a site of complex interactions between plants and microorganisms, where environmental factors such as soil physicochemical parameters as well as fertilizers or cultivation practices may have a large effect on microbial communities (Hindumathi and Reddy, 2011). The conservation of diversity of microflora in agricultural fields becomes very essential for the development of sustainable agriculture. This is why the study of interactions in the rhizosphere is a topic of current concern. Despite the importance of rhizosphere in agriculture and forestry, little work has been done regarding the distribution, diversity, and presence of microfungal flora in the soil associated with the brinjal, the vegetable crop in Telangana. The present work is aimed for quantitative and qualitative enumeration of the fungi from rhizosphere and nonrhizosphere soils of brinjal fields collected during different time intervals and to assess the percentage contribution and diversity of different fungal species.

\section{MATERIALS AND METHODS}

\section{Collection of Soil Samples}

Soil samples were collected from the rhizosphere and non-rhizosphere regions from agricultural brinjal fields at 
three intervals (pre-flowering, flowering, and harvesting period) of the life cycle. For rhizosphere soil sampling, the selected plants were carefully dugout with roots; excess soil was gently shaken off and discarded, leaving only the soil closely adhered to the root system. The roots were cut into pieces and placed in screw cap bottles containing sterile water for soil dilution. The bottles were shaken to remove closely adhering rhizosphere soil.

For the non-rhizosphere soil, samples were collected randomly from different places of experimental brinjal crop at a depth within $10 \mathrm{~cm}$ using a metal spatula and pooled together to get a composite sample. The rhizosphere and non-rhizosphere soil samples collected were stored at $4^{\circ} \mathrm{C}$ for further analysis.

\section{Soil Physicochemical Properties}

Soil $\mathrm{pH}$ was read using electronic digital $\mathrm{pH}$ meter. The moisture content of the soil sample was determined by oven-dried basis by drying $10 \mathrm{~g}$ of soil in a hot air oven at $105^{\circ} \mathrm{C}$ for $24 \mathrm{~h}$, and the dry weight was taken. Soil organic carbon was estimated by a colorimetric method (Anderson and Ingram, 1993).

\section{Dilution Plate Method}

Dilution agar plate technique (Waksman, 1922) was used to isolate the fungi from soil samples. $1 \mathrm{~g}$ of soil sample was diluted in $10 \mathrm{ml}$ of sterilized distilled water to make microbial suspension of $10^{-1}$ concentration. $1 \mathrm{ml}$ of this suspension was added to $9 \mathrm{ml}$ of sterilized distilled water to give $10^{-2}$ concentration. Similarly, serial dilutions were made to give concentrations up to $10^{-6}$. Triplicates of each dilution of $10^{-4}, 10^{-5}$, and $10^{-6}$ were used to isolate fungi. $1 \mathrm{ml}$ of each of the dilution was poured and spread on Petri plates containing sterilized potato dextrose agar (PDA) medium and CZA medium. One percent streptomycin solution was added to the medium before pouring into Petri plates for preventing bacterial growth. The plates were incubated in an inverted position at room temperature $\left(26 \pm 2{ }^{\circ} \mathrm{C}\right)$ for 3-5 days. Fungal colonies growing on the PDA and CZA plates were numbered. Each isolate of fungal species was sub-cultured by transferring onto fresh PDA slants.

The colonies growing on PDA and CZA plates with different morphology were counted separately. A portion from the growing edge of the colony was picked up with the help of a needle and mounted on a clean slide with lactophenol cotton blue stain. The specimen was spread carefully to avoid overcrowding of the fungal mycelium on the slide. The slide was gently heated over a flame of spirit lamp so as to facilitate the staining and remove air bubbles if any. The excess stain was removed with the help of tissue paper, and then, the cover glass was sealed with DPX. The slide was observed under the compound microscope. Photomicrographs of the individual fungal species were also taken.

\section{Identification}

Colony color and morphology were noted beside hyphal structure, spore size, shapes, and spore-bearing structures. They were identified using standard manuals (Gilman, 1957; Nagamani et al., 2006).

\section{Isolation and Enumeration of Fungi}

Serial dilution plate method (Johnson and Curl, 1972) was followed for the isolation of rhizosphere and nonrhizosphere fungi using PDA and CZA media. Colonyforming units (CFUs) of fungi were estimated by counting the number of fungal colonies. The CFU per gram soil was calculated on the dry weight basis:

$\mathrm{CFU} / \mathrm{g}^{-1}$ of soil $=$

Number of colonies per plate $\times$ Dilution factor

Dry weight of the soil taken

The percentage occurrence of each fungal species was calculated using the following formula:

Percentage occurrence of fungal species $=$

$\frac{\% \text { Occurrence of individual species }}{\% \text { Occurrence of total species }} \times 100$

$\%$ Occurrence of total species

\section{RESULTS AND DISCUSSION}

The data on rhizosphere and non-rhizosphere soil analysis of physicochemical characteristics presented in Table 1 show that the soil $\mathrm{pH}$ was neutral (7.1) to moderately alkaline (7.8). The soil moisture was relatively abundant in all soil samples ranging from $26.51 \%$ to $30.92 \%$. The soils were optimum in organic carbon ranging from medium $(0.5 \%$ to $0.75 \%)$ to high level $(>7.5 \%)$. The soil organic carbon ranged from $0.80 \%$ to $0.95 \%$ in the rhizosphere soil and $0.62-0.79 \%$ in the non-rhizosphere soil. Increase in soil organic carbon in the rhizosphere is affected by rhizodeposition, by which carbon enters the soil systems, forms symbiotic associations with fungi which facilitates the flow of carbon to and through this symbiotic interface, resulting in increased carbon content in the root region compared to the bulk soil (Leake et al., 2004). 
In the present study, fungal $\mathrm{CFU} / \mathrm{g}^{-1}$ soil exhibited variations throughout the sampling period in both rhizosphere as well as non-rhizosphere soils. Fungal CFU/ $\mathrm{g}^{-1}$ soil ranged from $1.18 \times 10^{5}$ to $1.90 \times 10^{5} \mathrm{~g}^{-1}$ dry soils in rhizosphere soil and $0.75 \times 10^{5}$ to $1.24 \times 10^{5} \mathrm{~g}^{-1}$ dry soils in the non-rhizosphere soil. Highest fungal CFU/ $\mathrm{g}^{-1}$ soil was observed at the harvesting stage of plant life cycle in rhizosphere $\left(1.90 \times 10^{5}\right)$ and at flowering stage in non-rhizosphere $\left(1.24 \times 10^{5}\right)$ soil in CZA medium (Table 2). It is evident from the data that there was an increase in $\mathrm{CFU} / \mathrm{g}^{-1}$ soil with increase in age of the plant growth period showing an association of highest propagule number during the time of flowering. The population of fungal flora showed lower $\mathrm{CFU} / \mathrm{g}^{-1}$ soil number in the non-rhizosphere than in corresponding rhizosphere soils and are affected by plant development. These results are in correlation with the earlier findings (Hindumathi and Reddy, 2011). It is evident from this study that fungal $\mathrm{CFU} / \mathrm{g}^{-1}$ soil is higher in the rhizosphere soil than that of the non-rhizosphere soil may be due to the different types of substances known as exudates released from the roots such as carbohydrates (sugars and oligosaccharides), organic acids, vitamins, nucleotides, flavonoids, enzymes, hormones, and volatile compounds (Prescott et al., 1999) that may have stimulated the microbial activities in the root region as compared to the non-rhizosphere soil. The root exudates stimulate the biological and physical interactions

Table 1: Physicochemical properties of rhizosphere and non-rhizosphere soils of brinjal

\begin{tabular}{lccc}
\hline Soil properties & \multicolumn{3}{c}{ Sampling period } \\
\cline { 2 - 4 } & PF & F & H \\
\hline pH & & & \\
R & 7.40 & 7.30 & 7.60 \\
NR & 7.80 & 7.20 & 7.50 \\
MC & & & \\
R & 30.40 & 30.92 & 29.48 \\
NR & 26.51 & 28.60 & 26.90 \\
OC & & & \\
R & 0.80 & 0.95 & 0.82 \\
NR & 0.75 & 0.79 & 0.62 \\
\hline
\end{tabular}

R: rhizosphere soil, NR: Non-rhizosphere soil, MC: Moisture content (\%), OC: Organic carbon (\%), PF: Pre-flowering, F: Flowering, H: Harvesting, organic carbon (low $<0.05 \%$; medium $0.5-0.75 \%$; high $>0.75 \%$ )

Table 2: Quantitative enumeration of fungi from non-rhizosphere and rhizosphere soils of brinjal

\begin{tabular}{lcccc}
\hline $\begin{array}{l}\text { Period of growth } \\
\text { in first column }\end{array}$ & \multicolumn{4}{c}{ Soil } \\
\cline { 2 - 5 } & \multicolumn{2}{c}{$\begin{array}{c}\text { Rhizosphere } \\
\text { CFU } / g^{-1} \text { soil }\end{array}$} & \multicolumn{2}{c}{$\begin{array}{c}\text { Non-rhizosphere } \\
\text { CFU } / \mathrm{g}^{-1} \text { soil }\end{array}$} \\
\cline { 2 - 5 } & PDA & CZA & PDA & CZA \\
\hline Period of growth & & & & \\
Before flowering & $1.59 \times 10^{5}$ & $1.18 \times 10^{5}$ & $0.75 \times 10^{5}$ & $0.82 \times 10^{5}$ \\
Flowering & $1.78 \times 10^{5}$ & $1.90 \times 10^{5}$ & $1.10 \times 10^{5}$ & $1.24 \times 10^{5}$ \\
Harvesting & $1.74 \times 10^{5}$ & $1.75 \times 10^{5}$ & $1.14 \times 10^{5}$ & $1.12 \times 10^{5}$ \\
\hline
\end{tabular}

Current Botany between roots and soil microorganisms which modify the biochemical and physical properties of the rhizosphere soil and contribute to root growth and plant survival, resulting in a dense and active microbial population in the root region (Khonglah et al., 2015).

The present study revealed the occurrence of 36 fungal species in the brinjal vegetable fields representing 15 genera. Among the 15 genera recorded, the genus Aspergillus was predominant represented by 14 species, followed by Fusarium (4 species), Trichoderma, Penicillium, and Cladospora by 2 species each. The other genera were represented by one species each (Table 1). The species of Aspergillus isolated were Aspergillus fischeri, Aspergillus flavipes, Aspergillus flavus, Aspergillus fumigatus, Aspergillus funiculosus, Aspergillus humicola, Aspergillus nidulans, Aspergillus niger, Aspergillus ochraceus, Aspergillus sulphureus, Aspergillus sydowii, Aspergillus tamarii, Aspergillus terreus, and Aspergillus versicolor; the species of Fusarium were Fusarium oxysporum, Fusarium poae, Fusarium solani, and Fusarium dimerum; the species of Cladophora were Cladosporium cladosporioides and Chaetomium herbarum; the species of Penicillium were Penicillium islandicum and Penicillium aurantiogriseum; Trichoderma spp. were Trichoderma harzianum and Trichoderma viride; and remaining were Alternaria sp., Macrophomina phaseolina, Monodictys fluctuate, Myrothecium roridum, Phoma glomerata, Rhizoctonia solani, Rhizopus stolonifer, Colletotrichum, and Chaetomium represented by one species each. White sterile and black sterile mycelia were also observed (Figures 1a-h and 2a-h).

Quantitatively species of the genus Aspergillus were predominant both in the rhizosphere and non-rhizosphere soils. A. fischeri, A. flavus, A. funiculosus, A. humicola, Aspergillus nidulans, A. niger, A. ochraceous, Aspergillus sulphureus, A. sydowii, Aspergillus tamarii, A.terreus, and $A$. versicolor were confined to rhizosphere. A. flavipes and A.fumigatus were observed in the non-rhizosphere soils. Alternaria, A. humicola, A. ochraceous, A. sydowii, A.tamarii, Chaetomium sp., F. dimerum, F. solani, and Monodictus sp. were not observed in non-rhizosphere soil but were found in rhizosphere. The present study results revealed the occurrence of saprophytes (Aspergillus and Penicillium), plant pathogens (Fusarium and Colletotrichum), and biocontrol agents (Trichoderma and Cladosporium) in the soil. F. oxysporum, F. poae, and F. solani were isolated from the soils of infected fields. The population density of these species was observed to be greater in rhizosphere than non-rhizosphere soils (Tables 3-5).

Aspergillus is observed to be an important component of the present rhizosphere and non-rhizosphere soil fungal flora constituting $70.54 \%$ and $58.96 \%$, respectively. 


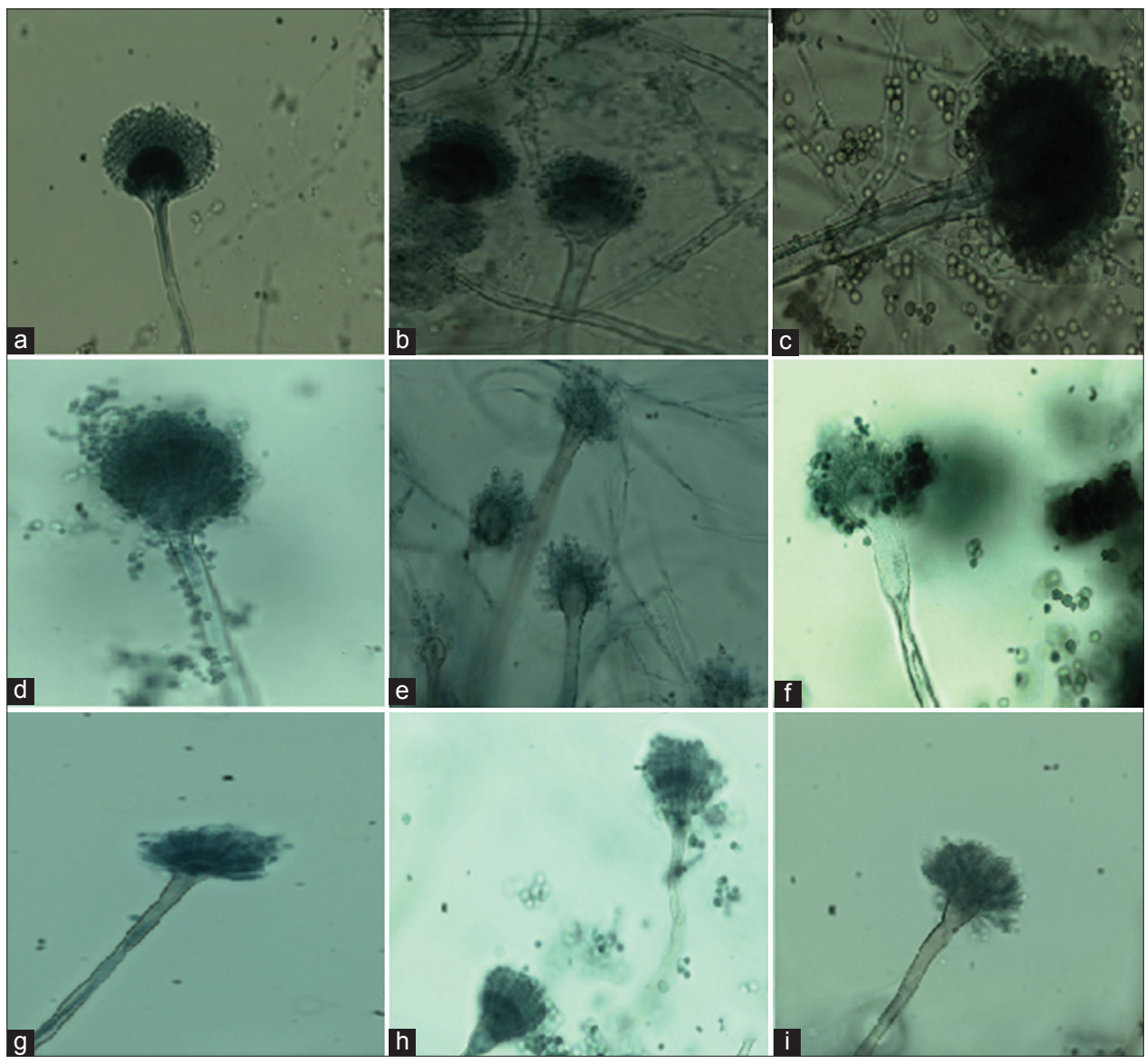

Figure 1: Photomicrographs of mycoflora isolated from rhizosphere and non-rhizosphere. (a) Aspergillus flavus, (b) Aspergillus terreus, (c) Aspergillus niger, (d) Aspergillus unguis, (e) Aspergillus sulphureus, (f) Aspergillus sp., (g) Aspergillus humicola, (h) Aspergillus ochraceus, (i) Aspergillus fischeri

Table 3: Percentage occurrence of mycoflora from rhizosphere soils of brinjal

\begin{tabular}{|c|c|c|c|c|c|c|c|}
\hline \multirow[t]{2}{*}{ Mycoflora } & \multicolumn{2}{|c|}{ Before flowering } & \multicolumn{2}{|c|}{ Flowering } & \multicolumn{2}{|c|}{ Harvesting } & \multirow[t]{2}{*}{ Total (\%) } \\
\hline & PDA & CZA & PDA & $\mathrm{CZA}$ & PDA & $\mathrm{CZA}$ & \\
\hline Alternaria alternata & 0 & 0 & 2 & 2 & 3 & 0 & $7(0.84)$ \\
\hline Aspergillus fischeri & 1 & 2 & 2 & 3 & 0 & 3 & $11(1.33)$ \\
\hline Aspergillus flavus & 17 & 6 & 4 & 6 & 12 & 13 & $58(7.03)$ \\
\hline Aspergillus funiculosus & 5 & 4 & 2 & 3 & 4 & 0 & $18(2.18)$ \\
\hline Aspergillus humicola & 0 & 0 & 2 & 5 & 2 & 0 & $9(1.09)$ \\
\hline Aspergillus nidulans & 0 & 0 & 13 & 3 & 8 & 9 & $33(4)$ \\
\hline Aspergillus niger & 37 & 31 & 28 & 20 & 22 & 22 & $160(19.39)$ \\
\hline Aspergillus ochraceous & 0 & 0 & 1 & 10 & 5 & 6 & $22(2.66)$ \\
\hline Aspergillus sulphureus & 0 & 0 & 2 & 3 & 3 & 4 & $12(1.45)$ \\
\hline Aspergillus sydowii & 0 & 0 & 2 & 2 & 3 & 3 & $10(1.21)$ \\
\hline Aspergillus tamarii & 0 & 0 & 1 & 2 & 2 & 1 & $6(0.72)$ \\
\hline Aspergillus terreus & 29 & 18 & 15 & 18 & 17 & 19 & $116(14.06)$ \\
\hline Aspergillus versicolor & 0 & 0 & 1 & 0 & 0 & 2 & $3(0.36)$ \\
\hline Chaetomium herbarum & 2 & 0 & 2 & 3 & 0 & 2 & $9(1.09)$ \\
\hline Cladosporium cladosporioides & 0 & 0 & 4 & 0 & 5 & 2 & $11(1.33)$ \\
\hline Cladospora herbarum & 0 & 5 & 1 & 5 & 3 & 2 & $16(1.93)$ \\
\hline Colletotrichum & 4 & 2 & 3 & 0 & 0 & 2 & $11(1.33)$ \\
\hline Curvularia clavata & 1 & 0 & 7 & 8 & 5 & 3 & $24(2.9)$ \\
\hline Fusarium dimerum & 0 & 2 & 1 & 2 & 0 & 2 & $7(0.84)$ \\
\hline Fusarium oxysporum & 4 & 3 & 9 & 8 & 8 & 10 & $42(5.09)$ \\
\hline Fusarium poae & 2 & 0 & 0 & 2 & 3 & 5 & $12(1.45)$ \\
\hline Fusarium solani & 0 & 0 & 2 & 3 & 0 & 2 & $7(0.84)$ \\
\hline Macrophomina phaseolina & 2 & 1 & 2 & 3 & 5 & 2 & $15(1.81)$ \\
\hline
\end{tabular}


Table 3: (Continued)

\begin{tabular}{|c|c|c|c|c|c|c|c|}
\hline \multirow[t]{2}{*}{ Mycoflora } & \multicolumn{2}{|c|}{ Before flowering } & \multicolumn{2}{|c|}{ Flowering } & \multicolumn{2}{|c|}{ Harvesting } & \multirow[t]{2}{*}{ Total (\%) } \\
\hline & PDA & CZA & PDA & $\overline{C Z A}$ & PDA & $\overline{C Z A}$ & \\
\hline Monodictys fluctuate & 0 & 0 & 2 & 8 & 3 & 5 & $18(2.18)$ \\
\hline Myrothecium roridum & 3 & 5 & 7 & 6 & 2 & 2 & $25(3.03)$ \\
\hline Penicillium aurantiogriseum & 3 & 0 & 3 & 3 & 4 & 5 & $18(2.18)$ \\
\hline Penicillium islandicum & 1 & 4 & 2 & 6 & 5 & 8 & $26(3.22)$ \\
\hline Rhizoctonia solani & 2 & 1 & 7 & 3 & 2 & 5 & $20(2.42)$ \\
\hline Rhizopus stolonifer & 0 & 0 & 3 & 0 & 3 & 2 & $8(0.96)$ \\
\hline Trichoderma harzianum & 3 & 0 & 3 & 2 & 2 & 3 & $13(1.57)$ \\
\hline Trichoderma viride & 9 & 1 & 4 & 4 & 4 & 3 & $25(3.03)$ \\
\hline Black mycelium sterile & 1 & 4 & 5 & 7 & 3 & 2 & $22(2.66)$ \\
\hline White mycelium sterile & 5 & 8 & 4 & 6 & 5 & 3 & $31(3.75)$ \\
\hline Total & 131 & 97 & 146 & 156 & 143 & 152 & $825(100)$ \\
\hline
\end{tabular}
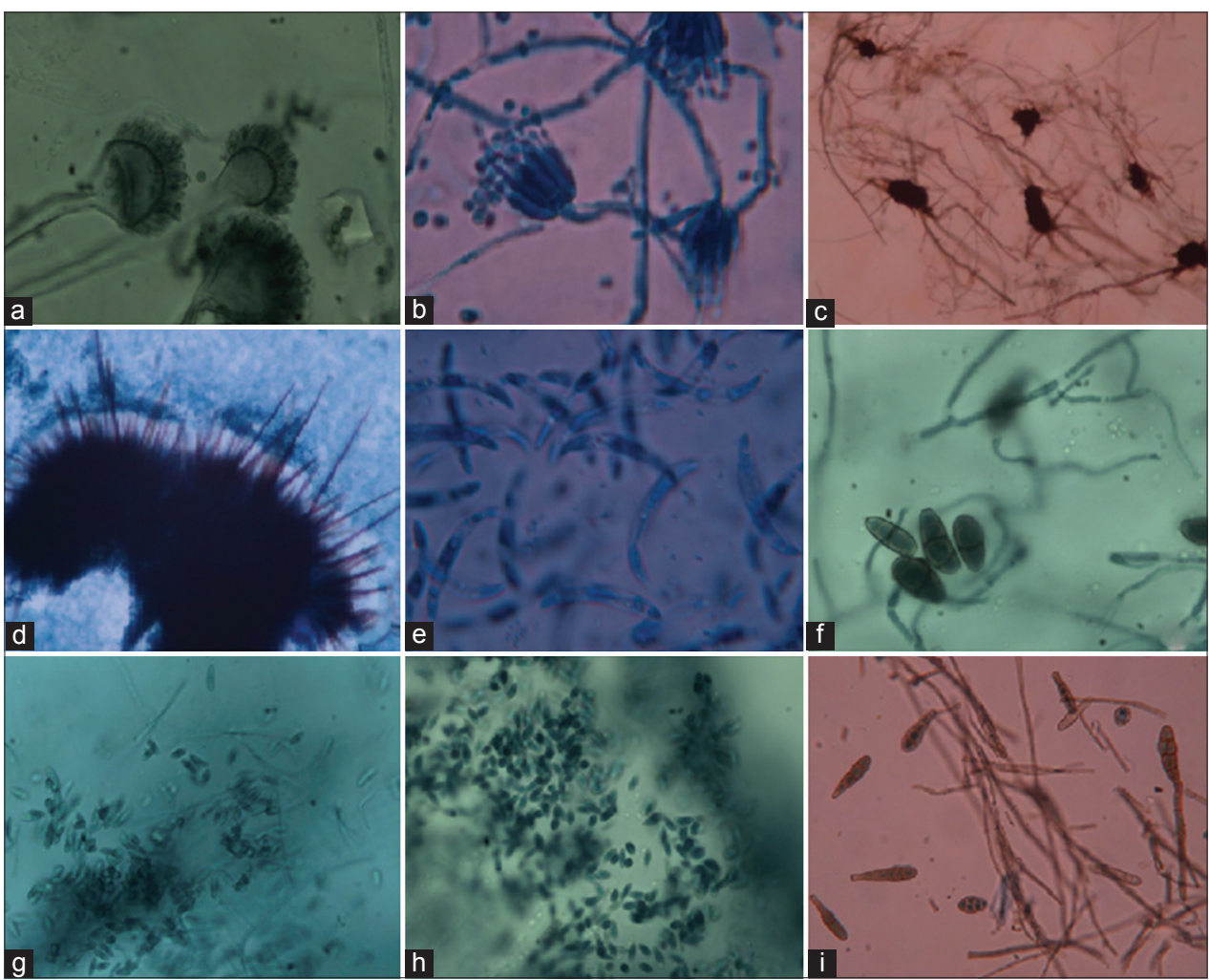

Figure 2: Photomicrographs of mycoflora isolated from rhizosphere and non-rhizosphere soils of brinjal. (a) Aspergillus fumigatus, (b) Penicillium sp., (c) Macrophomina phaseolina, (d) Colletotrichum falcatum, (e) Colletotrichum flacatum conidia, (f) Curvularia lunata, (g) Cladosporium cladosporioides, (h) Myrothecium sp., (i) Alternaria alternata

Among Aspergillus species, A. niger was the predominant occupant with percentage frequency of occurrence constituting $19.39 \%$ and $15.12 \%$ in rhizosphere and non-rhizosphere soils, respectively. Our observations are in agreement with those of Deshmukh et al. (2013) who reported the dominance of Aspergillus. In the rhizosphere, Fusarium populations were increased in number and occurrence, when compared to non-rhizosphere soils as plant growth was associated with root exudates with increasing plant age similar to earlier reports (Watanabeet al., 1974).
Fungal activities increased with plant age. In early plant growth stage (before flowering), the number of fungal $\mathrm{CFU} / \mathrm{g}^{-1} 0.75 \times 10^{5}$ increased progressively with the growth period. When near maturity, the $\mathrm{CFU} / \mathrm{g}^{-1}$ remained constant in rhizosphere attributed to the competitiveness between mycoflora. These observations are in agreement with those of Hindumathi and Reddy (2011).

In the present study, there was the occurrence of Trichoderma species, which would be a scope in using these fungi as a native biocontrol agent to suppress the plant pathogenic organisms (Ramaraju et al., 2016). 
Table 4: Percentage occurrence of mycoflora in from non-rhizosphere soils of brinjal field

\begin{tabular}{|c|c|c|c|c|c|c|c|}
\hline \multirow[t]{2}{*}{ Mycoflora } & \multicolumn{2}{|c|}{ Before flowering } & \multicolumn{2}{|c|}{ Flowering } & \multicolumn{2}{|c|}{ Harvesting } & \multirow[t]{2}{*}{ Total (\%) } \\
\hline & PDA & CZA & PDA & $\overline{C Z A}$ & PDA & $\overline{C Z A}$ & \\
\hline Aspergillus fischeri & 3 & 5 & 2 & 0 & 3 & 0 & $13(2.55)$ \\
\hline Aspergillus flavipes & 0 & 2 & 3 & 2 & 2 & 0 & $9(1.76)$ \\
\hline Aspergillus flavus & 8 & 9 & 15 & 11 & 12 & 13 & $68(13.35)$ \\
\hline Aspergillus fumigatus & 6 & 5 & 3 & 5 & 9 & 3 & $31(6.09)$ \\
\hline Aspergillus nidulans & 5 & 3 & 4 & 5 & 6 & 7 & $30(5.89)$ \\
\hline Aspergillus niger & 7 & 8 & 13 & 16 & 15 & 18 & $77(15.12)$ \\
\hline Aspergillus sulphureus & 2 & 0 & 3 & 4 & 3 & 4 & $16(3.14)$ \\
\hline Aspergillus terreus & 8 & 9 & 12 & 6 & 6 & 8 & $49(9.62)$ \\
\hline Aspergillus versicolor & 3 & 0 & 2 & 1 & 4 & 3 & $13(2.55)$ \\
\hline $\begin{array}{l}\text { Cladosporium } \\
\text { cladosporioides }\end{array}$ & 2 & 0 & 1 & 2 & 0 & 2 & $7(1.38)$ \\
\hline Cladosporium herbarum & 2 & 1 & 0 & 2 & 1 & 2 & $8(1.57)$ \\
\hline Colletotrichum falcatum & 0 & 2 & 0 & 0 & 2 & 0 & $4(0.78)$ \\
\hline Curvularia lunata & 0 & 4 & 2 & 3 & 3 & 0 & $12(2.35)$ \\
\hline Fusarium oxysporum & 2 & 3 & 4 & 6 & 5 & 4 & $24(4.71)$ \\
\hline Fusarium poae & 1 & 4 & 2 & 4 & 1 & 3 & $15(2.94)$ \\
\hline Macrophomina phaseolina & 2 & 2 & 3 & 5 & 2 & 3 & $17(3.33)$ \\
\hline Myrothecium roridum & 0 & 2 & 2 & 0 & 3 & 0 & $7(1.37)$ \\
\hline Penicillium aurantiogriseum & 2 & 0 & 3 & 4 & 1 & 2 & $12(2.35)$ \\
\hline Penicillium islandicum & 2 & 3 & 3 & 3 & 2 & 4 & $17(3.33)$ \\
\hline Phoma glomerata & 0 & 0 & 3 & 4 & 0 & 1 & $8(1.57)$ \\
\hline Phoma glomerata & 2 & 0 & 2 & 2 & 4 & 2 & $12(2.35)$ \\
\hline Rhizoctonia solani & 0 & 0 & 2 & 2 & 2 & 3 & $9(1.76)$ \\
\hline Rhizopus stolonifer & 0 & 0 & 0 & 2 & 0 & 1 & $3(0.59)$ \\
\hline Trichoderma harzianum & 0 & 2 & 2 & 3 & 2 & 1 & $10(1.96)$ \\
\hline Trichoderma viride & 2 & 0 & 0 & 2 & 1 & 2 & $7(1.37)$ \\
\hline Black mycelium sterile & 3 & 2 & 2 & 4 & 2 & 3 & $16(3.14)$ \\
\hline White mycelium sterile & 0 & 2 & 3 & 4 & 3 & 3 & $15(2.94)$ \\
\hline Total & 62 & 68 & 91 & 102 & 94 & 92 & $509(100)$ \\
\hline
\end{tabular}

Table 5: Abundance of mycoflora in rhizosphere and non-rhizosphere soils of brinjal

\begin{tabular}{|c|c|c|}
\hline Mycoflora & Rhizosphere & Non-rhizosphere \\
\hline Alternaria alternata & + & - \\
\hline Aspergillus fischeri & + & + \\
\hline Aspergillus flavus & ++ & +++ \\
\hline Aspergillus flavipes & - & + \\
\hline Aspergillus funiculosus & + & + \\
\hline Aspergillus fumigatus & + & + \\
\hline Aspergillus humicola & + & - \\
\hline Aspergillus nidulans & + & + \\
\hline Aspergillus niger & +++ & +++ \\
\hline Aspergillus ochraceous & + & - \\
\hline Aspergillus sulphureus & + & + \\
\hline Aspergillus sydowii & + & - \\
\hline Aspergillus tamarii & + & - \\
\hline Aspergillus terreus & +++ & ++ \\
\hline Aspergillus versicolor & + & + \\
\hline Chaetomium globosum & + & - \\
\hline $\begin{array}{l}\text { Cladosporium } \\
\text { cladosporioides }\end{array}$ & + & + \\
\hline Cladosporium herbarum & + & + \\
\hline Colletotrichum falcatum & + & + \\
\hline Curvularia clavata & + & + \\
\hline Fusarium dimerum & + & - \\
\hline Fusarium oxysporum & ++ & + \\
\hline Fusarium poae & + & + \\
\hline Fusarium solani & + & - \\
\hline Macrophomina phaseolina & + & + \\
\hline Monodictys fluctuate & + & - \\
\hline Myrothecium roridum & + & + \\
\hline Penicillium aurantiogriseum & + & + \\
\hline
\end{tabular}

(Contd...)
Table 5: (Continued)

\begin{tabular}{lll}
\hline Penicillium islandicum & + & + \\
Phoma glomerata & - & + \\
Rhizoctonia solani & + & + \\
Rhizopus stolonifer & + & + \\
Trichoderma harzianum & + & + \\
Trichoderma viride & + & + \\
Sterile black mycelium & + & + \\
Sterile white mycelium & + & + \\
\hline
\end{tabular}

Detected isolates: $+++:$ High (11 and above), ++ : Medium (6-10), + : Low (1-5)

\section{CONCLUSION}

The fungal numbers and species varied in relation to plant growth stage as well as rhizosphere and nonrhizosphere soils. This type of studies help in better understanding of the conditions favorable for the occurrence of soilborne fungal pathogens and enable us to take possible precautions to prevent the establishment and control of fungal pathogens, thereby reducing loss. Lewis and Papavizas (1985) mentioned that Trichoderma in natural soil requires substrates as a source of nutrients to enhance growth, survival, and competitiveness. The conservation of diversity of mycoflora in agricultural fields becomes very essential for the development of sustainable agriculture. 


\section{REFERENCES}

Alexopoulos CJ, Mims CW. Introductory Mycology. $3^{\text {rd }}$ ed. New York: John Wiley and Sons, Inc.; 1979.

Anderson JM, Ingram JS. Tropical Soil Biology and Fertility: A Handbook of Methods of Analysis. $2^{\text {nd }}$ ed. UK, Oxford, Wallingford: CAB International; 1993. p. 1694-7.

Aneja KR. Biochemical activities of microorganism, experiments. In: Microbiology, Plant Pathology and Biotechnology. $4^{\text {th }}$ ed. India: New Age International Publishers; 2001. p. 157-62.

Chotte JL, Ladd JN, Amato M. Sites of microbial assimilation, and turnover of soluble and particulate 14C-labelled substrates decomposing in a clay soil. Soil Biol Biochem 1997;30:205-18.

Deshmukh RB, Dange SS, Jadhav PV, Deokule SS, Patil NA. Studies on the mycoflora in the rhizosphere of sugarcane (Saccharum officinarum L.). Int J Bioassays 2013;2:674-6.

Feller C, Beare MH. Physical control of soil organic matter dynamics in the tropics. Geoderma 1997;79:69-116.

Gaddeyya G, Niharika PS, Bharathi P, Kumar PR. Isolation and identification of mycoflora in different crop fields at Salur Mandal. Adv Appl Sci Res 2012;3:2020-6.

Gilman JC. A Manual of Soil Fungi. $2^{\text {nd }}$ ed. Ames: The Iowa State University Press; 1957.

Hindumathi A, Reddy BN. Occurrence and distribution of arbuscular mycorrhizal fungi and microbial flora in the rhizosphere soils of mungbean [Vigna radiata (L.) wilczek] and soybean [Glycine max (L.) Merr.] from Adilabad, Nizamabad and Karimnagar districts of Andhra Pradesh state, India. Adv Biosci Biotech 2012;2:275-86.

Johnson LF, Curl EH. Methods for Research on the Ecology of Soil Borne Plant Pathogens. Minneapolis: Burgress Publishing Co.; 1972. p. 247.
Khonglah D, Devi HR, Dkhar MS. Diversity of culture dependent mycoflora of the rhizosphere and non rhizosphere soil of maize (Zea Mays L.). Int J Adv Agric Sci Technol 2015;4:86-95.

Kowalchuk GA, Buma DS, de BoerW, Klinkhamer PG, van Veen JA. Effects of above-ground plant species composition and diversity on the diversity of soil-borne microorganisms. Antonie Van Leeuwenhoek 2002;81:509-20.

Leake JR, Johnson D, Donnelly DP, Muckle GE, Boddy L, Read DJ. Networks of power and influence: The role of mycorhizal mycelium in controlling plant communities and agrosystem functioning. Can J Bot 2004;82:1016-45.

Lewis JA, Papavizas GC. Effect of mycelial preparations of Trichoderma and Gliocladiumon populations of Rhizoctonia solani and incidence of damping-off. Phytopathology 1985;75:812-7.

Nagamni A, Kunwar K, Manoharachary C. Hand Book of Soil Fungi. India: I. K. International Pvt. Ltd.; 2006.

Prescott L, Harley J, Klein DA. Microbiology. Boston: McGraw-Hill; 1999.

Ramaraju C, Hindumathi A, Reddy BN. In vitro antagonistic activity of Trichoderma and Penicillium species against Macrophomina phaseolina (Tassi) Goid. Ann Bio Res 2016;7:34-8.

Tisdall JM, Oades JM. Organic matter and water-stable aggregates in soils. J Soil Sci 1982;33:141-63.

Waksman SA. A method for counting the number of fungi in the soil. J Bacteriol 1922;7:339-41.

Warcap JH. The soil-plate method for isolation of fungi from soil. Nature 1951;166:117-66.

Watanabe T, Tzean SS, Leu LS. Fungi isolated from the underground parts of sugarcane in relation to the poor ratooning in Taiwan. Trans Mycol Soc Jpn 1974;15:30-41. 